\title{
Reações adversas a meios de contraste iodados
}

\section{Adverse reactions to iodinated contrast media}

Data de receção / Received in: 29/01/2016

Data de aceitação / Accepted for publication in: I2/12/2017

\author{
Rev Port Imunoalergologia 2019;27 (1):9-20
}

João Marcelino ${ }^{1,2}$, Sara Carvalhol,2, Fátima Cabral Duarte ${ }^{1,2}$, Ana Célia Costa ${ }^{1,2}$, Manuel Pereira Barbosa $a^{1,2}$

I Serviço de Imunoalergologia, Hospital de Santa Maria, Centro Hospitalar Lisboa Norte

${ }^{2}$ Clínica Universitária de Imunoalergologia, Faculdade de Medicina da Universidade de Lisboa

\section{RESUMO}

Os meios de contraste radiológico iodados (MCRI) são os meios de contraste mais usados em radiologia e são cada vez mais utilizados na prática clínica. A ocorrência de reações adversas a MCRI é muitas vezes desvalorizada, podendo colocar o doente em risco numa posterior utilização ou, pelo contrário, sobrevalorizada, condicionando restrições desnecessárias. O reconhecimento precoce das reações adversas, assim como a sua fisiopatologia, fatores de risco, abordagem diagnóstica e abordagem terapêutica, são essenciais para um correto manejo dos MCRI. Por esta razão é importante a divulgação deste tema em Imunoalergologia, pela necessidade de abordar e orientar corretamente estes casos.

Palavras-chave: Meios de contraste radiológico iodados, reações adversas, reações imediatas, reações tardias, testes cutâneos.

\section{ABSTRACT}

lodinated contrast media (ICM) are the most common contrast agents used in modern radiology and they are becoming more commonly used in medical practice. The occurrence of adverse reactions is frequently undervalued, placing the patient at risk for further exposure. On the other hand, reactions can be overvalued, conditioning unnecessary restrictions. Early recognition of adverse reactions, knowledge of their physiopathology, risk factors and therapeutic approach are essential for a correct management of ICM. This is why it is important to divulge this knowledge among imunoallergologists, who will need to evaluated and treat these cases.

Key-words: lodinated contrast media, adverse reactions, immediate reactions, late reactions, skin tests. 


\section{INTRODUÇÃO}

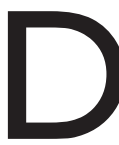
esde as últimas décadas do século $X X$ que o desenvolvimento de técnicas de investigação $e$ diagnóstico tem transformado a prática clínica. Uma das grandes alterações foi a introdução de meios de contraste radiológico (MCR) na prática médica.

Atualmente, os MCR são dos fármacos mais usados na medicina moderna de diagnóstico e, entre eles, salientam-se os meios de contraste radiológico iodados (MCRI), pela maior frequência de utilização.

O primeiro exame radiológico efetuado com MCRI foi uma angiografia em 1920. Durante o século XXI, os MCRI evoluíram, de agentes iónicos de elevada osmolalidade, para não iónicos de baixa osmolalidade, condicionando uma redução progressiva no número de reações adversas desencadeadas por estes agentes. Por um lado, a ocorrência das mesmas continua a ser desvalorizada/ /subdiagnosticada pelos profissionais de saúde que manipulam estes produtos. Por outro, existem ideias erradas disseminadas (como considerar fator de risco a rinite e a coexistência de alergia a marisco) que levam a uma atitude demasiado preventiva/restritiva na utilização destes produtos, adiando desnecessariamente a realização de exames radiológicos importantes.

Com este artigo, os autores alertam para a necessidade da atualização de conhecimentos nesta área, pelo que apresentam uma revisão dos vários aspetos subjacentes, nomeadamente a classificação dos MCRI, assim como fisiopatologia, fatores de risco, abordagem diagnóstica e terapêutica de reações adversas a estes produtos.

\section{CLASSIFICAÇÃO DOS MEIOS DE CONTRASTE RADIOLÓGICO IODADO}

Todos os MCRI têm em comum o anel de benzeno tri-iodado nas posições 2, 4 e 6, diferindo apenas no número destes anéis por molécula e nos radicais que cada anel apresenta. Os radicais tornam a molécula menos

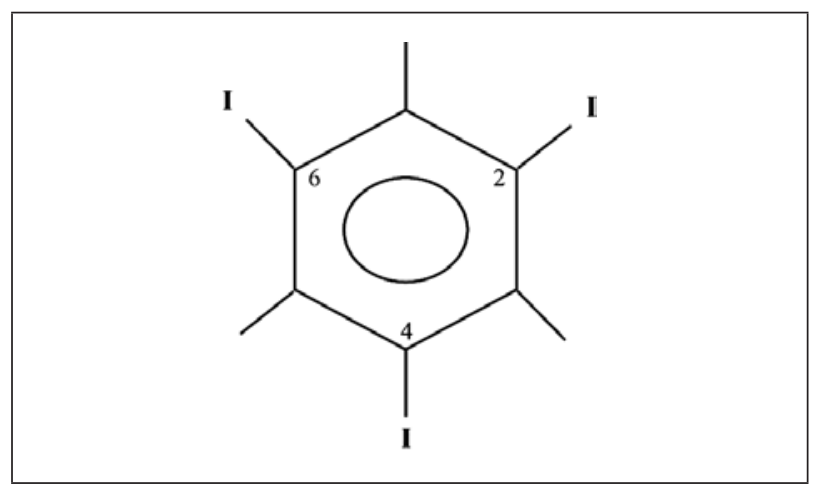

Figura I. Anel de benzeno tri-iodado que constitui a unidade-base dos meios de contraste iodados ${ }^{1,2,3}$.

tóxica, aumentam a solubilidade do anel de benzeno lipofílico e são responsáveis pelas propriedades individuais de cada MCRI (Figura I) 1,2,3.

Os MCRI inicialmente sintetizados apresentavam uma osmolalidade 5 a 8 vezes superior ao plasma, razão pela qual eram designados MCRI de elevada osmolalidade (HOCM). Os MCRI mais recentes apresentam uma osmolalidade muito inferior e mais fisiológica ( 2 a 3 vezes a osmolalidade do plasma) e são designados MCRI de baixa osmolalidade (LOCM)!.

É a partir destes dois pontos descritos (estrutura e osmolaridade) que se faz a classificação dos MCRI (Quadro I) ${ }^{3}$.

De um modo geral, todos estes compostos não são reativos, têm baixa ligação proteica e são excretados, não metabolizados, na urina até 24 horas após a sua administração.

\section{CLASSIFICAÇÃO E EPIDEMIOLOGIA DAS REAÇÕES ADVERSAS AOS MEIOS DE CONTRASTE RADIOLÓGICO IODADO}

As reações adversas aos MCRI foram descritas pela primeira vez em meados da década de 80 . Atualmente, de acordo com Brockow et al. ${ }^{4}$, as reações adversas aos MCRI classificam-se em três tipos (Figura 2): I) Reações tóxicas: relacionadas com as características moleculares do MCRI, que são responsáveis pela quimiotoxicidade, 
Quadro I. Classificação dos meios de contraste radiológico iodados $^{3}$

\begin{tabular}{|c|c|c|}
\hline DCl & Nome comercial & $\begin{array}{c}\text { Osmolalidade } \\
\left(\mathrm{mOsm} / \mathrm{kg} \text { de } \mathrm{H}_{2} \mathrm{O}\right)\end{array}$ \\
\hline \multicolumn{3}{|c|}{ Monómoros iónicos tri-iodados de elevada osmolalidade } \\
\hline Amidotrizoato & Radioselectan ${ }^{\circledR}$ & 2100 \\
\hline loxitalamato & Telebrix $^{\circledR}$ & 1710 \\
\hline \multicolumn{3}{|c|}{ Dímeros iónicos hexaiodados de baixa osmolalidade } \\
\hline loxaglato & Hexabrix $^{\circledR}$ & 600 \\
\hline \multicolumn{3}{|c|}{$\begin{array}{c}\text { Monómoros não iónicos tri-iodados de baixa } \\
\text { osmolalidade }\end{array}$} \\
\hline lopamidol & lopamiron $^{\circledR}$ & 616 \\
\hline lohexol & Omnipaque ${ }^{\circledR}$ & 640 \\
\hline lomeprol & lomeron ${ }^{\circledR}$ & 521 \\
\hline lopentol & Ivepaque ${ }^{\circledR}$ & 640 \\
\hline loversol & Optiray ${ }^{\circledR}$, Optiject $^{\circledR}$ & 630 \\
\hline lopromida & Ultravist $^{\circledR}$ & 607 \\
\hline lobitridol & Xenetix $^{\circledR}$ & 695 \\
\hline \multicolumn{3}{|c|}{ Dímeros não iónicos hexaiodados iso-osmolares } \\
\hline $\begin{array}{l}\text { lodixanol } \\
\text { lotrolan }\end{array}$ & $\begin{array}{l}\text { Visipaque }{ }^{\circledR} \\
\text { Isovist }^{\circledR}\end{array}$ & 290 \\
\hline
\end{tabular}

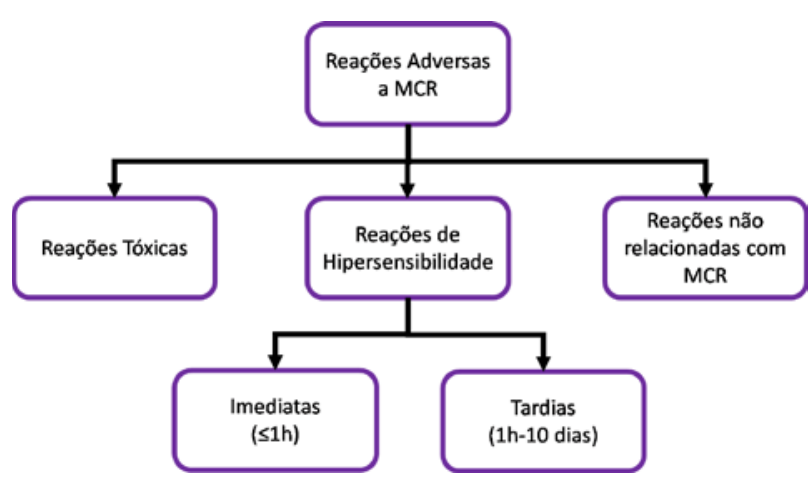

Figura 2. Classificação das reações adversas a meios de contraste iodados ${ }^{4,5}$

osmotoxicidade ou ligação molecular a ativadores moleculares. Não são reações de hipersensibilidade, mas uma resposta fisiológica ao MCRI dependente da dose e con- centração ${ }^{4,5}$; 2) Reações não relacionadas com MCRI: ocorrem durante o período de tempo espectável para reações adversas a MCRI, mas têm outra causa; 3) Reações de hipersensibilidade alérgicas e não alérgicas: são definidas pela Academia Europeia de Alergia e Imunologia Clínica (EAACl) como "Conjunto de sintomas e/ou sinais objetivos e reprodutíveis, iniciados após exposição a um estímulo definido numa dose tolerada por indivíduos normais" ${ }^{\prime 46}$. Estão incluídas as reações que envolvem o sistema imunitário (imunológicas) e as sem mecanismo imunológico subjacente (não imunológicas). Estas últimas, no passado denominadas reações anafilactoides, "alérgicas-like" ou idiossincráticas, são dependentes da dose e da concentração, e ocorrem a partir de um determinado limiar de fármaco 4,5 . Relativamente ao timming de ocorrência, as reações adversas consideram-se imediatas quando ocorrem até I hora após a administração do MCRI ou tardias, quando ocorrem entre I hora e I0 dias após a administração do $M C R I^{4}$.

Além de imediatas ou tardias, as reações podem ser classificadas de acordo com a sua gravidade. A gravidade das reações imediatas costuma ser classificada segundo a escala de Ring e Messmer (Quadro 2) 4 . Quanto à classificação das reações tardias, não existe um critério único para as definir. Uma possível forma de classificação usada por alguns autores é a seguinte ${ }^{4}$ : ligeira se não houver necessidade de terapêutica; moderada se for necessário tratamento, mas o doente responde rápida e adequadamente ao mesmo; e grave se for necessário internamento, podendo mesmo conduzir à morte.

A prevalência exata das reações adversas a MCRI é desconhecida devido à constante evolução dos MCRI usados $^{7}$, à dificuldade no diagnóstico (uma vez que os sintomas podem estar relacionados com patologias médicas concomitantes e/ou terapêuticas simultâneas) e devido à inexistência de um registo obrigatório para a declaração destas reações, tornando-as subdiagnosticadas e subreportadas ${ }^{3,5,8}$. Apesar destas dificuldades, sabe-se que com a passagem dos HOCM para os LOCM a frequência de efeitos adversos por MCRI diminuiu acentua- 
João Marcelino, Sara Carvalho, Fátima Cabral Duarte, Ana Célia Costa, Manuel Pereira Barbosa

Quadro 2. Classificação das reações imediatas a meios de contraste radiológico iodados de acordo com Ring e Messmer 5 .

\begin{tabular}{|c|c|c|c|c|}
\hline \multirow{2}{*}{ Grau } & \multicolumn{4}{|c|}{ Sintomas } \\
\hline & Cutâneos & Abdómen & Respiratório & Cardiovascular \\
\hline $\mathbf{I}$ & $\begin{array}{l}\text { Prurido } \\
\text { Eritema } \\
\text { Urticária } \\
\text { Angioedema }\end{array}$ & & & \\
\hline II & $\begin{array}{c}\text { Prurido } \\
\text { Eritema } \\
\text { Urticária } \\
\text { Angioedema }\end{array}$ & $\begin{array}{c}\text { Náuseas } \\
\text { Dor }\end{array}$ & $\begin{array}{l}\text { Rinorreia } \\
\text { Rouquidão } \\
\text { Dispneia }\end{array}$ & Taquicardia $(\Delta>20 / \mathrm{min})$ \\
\hline III & $\begin{array}{l}\text { Prurido } \\
\text { Eritema } \\
\text { Urticária } \\
\text { Angioedema }\end{array}$ & $\begin{array}{l}\text { Vómitos } \\
\text { Diarreia }\end{array}$ & $\begin{array}{c}\text { Edema laríngeo } \\
\text { Broncospasmo } \\
\text { Cianose }\end{array}$ & $\begin{array}{c}\text { Hipotensão }(\Delta>20 / \mathrm{mmHg} \\
\text { sistólica }) \\
\text { Arritmia } \\
\text { Choque }\end{array}$ \\
\hline IV & $\begin{array}{l}\text { Prurido } \\
\text { Eritema } \\
\text { Urticária } \\
\text { Angioedema }\end{array}$ & $\begin{array}{l}\text { Vómitos } \\
\text { Diarreia }\end{array}$ & Paragem respiratória & Paragem cardiocirculatória \\
\hline
\end{tabular}

$\Delta$ - variação.

damente ${ }^{5}$. Talvez um pouco relacionado com esta mudança, as reações tardias são atualmente mais comuns do que as imediatas (embora no passado as imediatas tenham sido mais reportadas do que as tardias) ${ }^{18}$.

$\mathrm{Na}$ população adulta, as reações adversas imediatas ligeiras (sem perigo para vida e sem necessidade de internamento) ocorrem em 3,8-12,7\% das administrações endovenosas de HOCM e 0,7-3,1\% das de LOCM. As reações adversas imediatas graves ocorrem em $0,1-0,4 \%$ das administrações endovenosas de HOCM e 0,02-0,04\% das de LOCM $2,4,5,10,11$. Na população pediátrica, a frequência de reações imediatas é de 0,18-0,46\% com a administração endovenosa de $\mathrm{LOCM}^{5}$. Um dos estudos mais relevantes sobre a prevalência de reações imediatas é o prospetivo multicêntrico realizado por Katayamana no Japão em 1990 (Quadro 3) ${ }^{12}$.

Relativamente às reações adversas tardias, têm uma prevalência ente 0,5 e $23 \% 4,5,7$. Apesar de poderem ocorrer até ao $7 .^{\circ}$ dia, $\leq 4 \%$ ocorre nas primeiras I-24 horas e $>50 \%$ das reações ocorre nos primeiros três dias ${ }^{7}$.
Em termos de mortalidade, apesar de as reações adversas a LOCM serem, em geral, menos graves que a HOCM, a mortalidade de ambas é semelhante, cerca de I/100 000 administrações ${ }^{2,4}$.

Quanto ao MCRI mais associado a reações adversas, o iodixanol é o mais frequentemente referido na literatura. Num grande estudo multicêntrico ${ }^{10} \mathrm{com} 220$ doentes, o iodixanol surge associado a reações tardias em número significativamente superior a outros MCRI, se-

Quadro 3. Prevalência de reações adversas a meios de contraste iodados ${ }^{\prime \prime}$

\begin{tabular}{|l|l|l|}
\hline & HOCM & \multicolumn{1}{|c|}{ LOCM } \\
\hline Doentes (n) & 169.284 & 168.363 \\
\hline Número de reações (\%) & 12,66 & 3,13 \\
\hline Reações graves (\%) & 0,22 & 0,04 \\
\hline Reações muito graves (\%) & 0,04 & 0,004 \\
\hline Mortes (\%) & 0,0006 & 0,0006 \\
\hline
\end{tabular}


guido pelo iomeprol. Apesar de este e outros artigos ${ }^{5,11}$ referirem o iodixanol como tendo maior probabilidade de causar reações tardias, nenhum artigo descreve as frequências relativas do uso de cada um dos diferentes MCRI. Os resultados referidos podem dever-se, apenas, ao facto do iodixanol ser mais usado que outros MCRI.

\section{FISIOPATOLOGIA}

O mecanismo fisiopatológico das reações adversas a MCRI é diferente consoante se trate de uma reação imediata ou tardia.

No caso das reações imediatas, múltiplos estímulos - ocorrendo isolados ou em simultâneo - podem desencadear a reação. Um deles é a osmolaridade. Os primeiros MCRI (HOCM) eram hipertónicos. Um fluido hiperosmolar, independentemente da sua composição, causa vasodilatação, aumento da permeabilidade capilar, cárdio e nefrotoxicidades diretos e desgranulação mastocitária. Por induzirem a libertação direta de histamina pelos mastócitos e basófilos, estas reações manifestam-se de forma semelhante às reações alérgicas mediadas por $\lg ^{13}$. Este mecanismo explica as reações como sensação de calor ou dor no local da administração, náuseas, vómitos ou mal-estar geral ${ }^{13}$. O aparecimento dos LOCM, por terem menor osmolalidade, permitiu uma redução significativa no número destas reações adversas ${ }^{13}$.

Outro mecanismo fisiopatológico envolvido é a capacidade de a própria molécula do contraste induzir a desgranulação inespecífica de mastócitos e basófilos. Este facto foi demonstrado in vitro por Stellato et al. ${ }^{14}$ que observaram diferentes graus de ativação dos mastócitos entre os MCRI testados, não sendo estas diferenças passíveis de explicação unicamente pela sua concentração ou osmolalidade ${ }^{12,14}$.

Outros mecanismos envolvem a ativação, inativação ou inibição de mediadores vasoativos ${ }^{5,8}$. Em resumo, os mecanismos envolvidos nas reações imediatas são: I) efeito membranar direto, relacionado com a osmolalida- de e estrutura química do $\left.M C R\right|^{3,4,12-15} ; 2$ ) mecanismo mediado por $\lg ^{3,4}$, evidenciado por testes cutâneos positivos, identificação de lgE específicas para alguns MCRI (loxaglato e loxitalamato) e a clínica desenvolvida por alguns doentes com reações anafiláticas reprodutíveis após a reexposição ${ }^{3}$;) ativação do sistema de complemento através da via alternativa formando $\mathrm{C} 3 \mathrm{a}$ e $\mathrm{C} 5 \mathrm{a}^{16-18}$ ou da via clássica ${ }^{9}$, 9 ; e 4) ativação do sistema da cinina e bradicinina por inibição direta da enzima conversora da angiotensina $^{16}$.

Relativamente às reações de hipersensibilidade tardias, estas são mediadas por células T. A ativação dos linfócitos T é suportada por várias evidências: I) existência de testes epicutâneos e intradérmicos tardios positivos; 2) presença de infiltrados de células $T$ na derme dos locais com reação positiva aos testes cutâneos; 3) reaparecimento da erupção cutânea após prova de provocação; 4) capacidade de os MCRI estimularem a proliferação de linfócitos T periféricos em doentes com erupções cutâneas induzidas por MCRI ${ }^{12,16,20}$.

\section{CLÍNICA E FATORES DE RISCO}

As manifestações clínicas das reações adversas são bastante heterogéneas (Quadro 4). Este facto dificulta a capacidade de atribuir como etiologia da reação o MCRI administrado e não outra patologia ou fármaco administrado em concomitância. Este problema é especialmente evidente nas reações tardias, em que o intervalo de tempo entre a administração do MCRI e o aparecimento dos sintomas pode ir até 10 dias. Um estudo de 2003 relatou que $50 \%$ das reações adversas tardias não se relacionavam verdadeiramente com o $\mathrm{MCRI}^{7}$, o que demonstrou a importância do estudo imunoalergológico destes doentes na identificação de verdadeiras reações imunológicas aos MCRI.

Relativamente às reações imediatas, $70 \%$ ocorrem nos primeiros 5 minutos após administração do MCRI e $96 \%$ das reações graves ou fatais manifestam-se nos pri- 
Quadro 4. Manifestações clínicas das reações imediatas e tardias a meios de contraste radiológico iodados ${ }^{5}$.

\begin{tabular}{|l|l|}
\hline \multicolumn{1}{|c|}{ Reações imediatas } & \multicolumn{1}{c|}{ Reações tardias } \\
\hline $\begin{array}{l}\text { Prurido e urticária } \\
\text { (ocorrem em 70\% doentes } \\
\text { com reações imediatas) }\end{array}$ & $\begin{array}{l}\text { Exantema cutâneo } \\
\text { (ocorrem em 50\% doentes } \\
\text { com reações tardias) }\end{array}$ \\
\hline Angioedema & Prurido e urticária \\
\hline Eritema & Angioedema \\
\hline Náuseas & Eritema multiforme minor \\
\hline Diarreia & Eritema fixo \\
\hline Dor abdominal & Síndrome Stevens-Johnson \\
\hline Rinite & Necrólise epidérmica tóxica \\
\hline Rouquidão & Vasculite cutânea \\
\hline Tosse & $\begin{array}{l}\text { SDRIFE (Symmetrical drug } \\
\text { related intertriginous and } \\
\text { flexural exanthema) }\end{array}$ \\
\hline $\begin{array}{l}\text { Dispneia / broncospasmo / } \\
\text { edema laríngeo }\end{array}$ & $\begin{array}{l}\text { DRESS (Drug Reaction with } \\
\text { Symophilia and Systemic }\end{array}$ \\
\hline $\begin{array}{l}\text { Hipotensão / taquicardia / } \\
\text { arritmia }\end{array}$ & Sintomas gastrointestinais \\
\hline Choque cardiovascular & Outras manifestações \\
\hline Paragem cardiorrespiratória & Syms \\
\hline
\end{tabular}

meiros 20 minutos $^{21}$. As reações imediatas são predominantemente mucocutâneas, de gravidade ligeira e autolimitadas ${ }^{4,21}$.

As reações tardias são predominantemente ligeiras e os sintomas mais frequentes são cutâneos, principalmente exantemas (>50\% das reações tardias), prurido, cefaleias, náuseas, tonturas, febre e alterações gastroin-

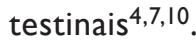

O principal fator de risco para reação adversa a MCRI é a história de uma reação prévia. Doentes com reações prévias têm um risco de $21-60 \%{ }^{4}$ (ou 10-35\% segundo outros autores ${ }^{5}$ ) de desenvolverem reação numa exposição posterior. Quando reatores prévios a HOCM são expostos a um LOCM há uma redução de dez vezes na incidência de reações graves ${ }^{4,5}$. Um estudo multicêntrico com 220 doentes mostrou que $62 \%$ dos doentes com reações imediatas e $49 \%$ de doentes com reações tardias apresentavam história de reação prévia a MCRI ${ }^{10}$.

Outros fatores de risco descritos na literatura por diversos autores encontram-se descritos no Quadro 5. Contudo, nenhuma destas condições é uma contraindicação absoluta para a administração de MCRI.

É importante referir que a alergia a marisco e a produtos contendo iodo são muitas vezes falsamente considerados fatores de risco para reações adversas. Estes mitos tiveram origem nos anos 1970 em trabalhos

Quadro 5. Fatores de risco para reações adversas a MCRI

\begin{tabular}{|c|c|}
\hline Fatores dependentes do doente & Género feminino $7,5,8,33$; crianças $^{1} ;>60$ anos $^{1}$ \\
\hline Fatores dependentes do MCR & $\begin{array}{l}\text { Uso }>20 \mathrm{mg} \text { de iodo no total'; taxa de administração do } M C R \text { mais rápida'; uso de via } \\
\text { arterial em comparação com endovenosa' }\end{array}$ \\
\hline Patologias concomitantes & 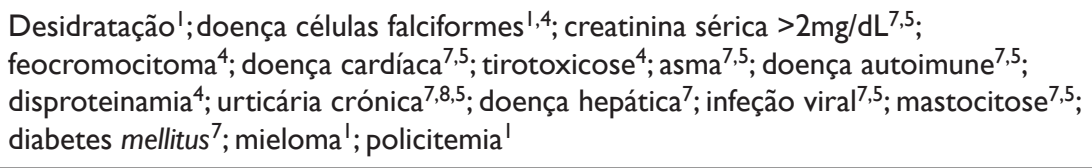 \\
\hline Fármacos concomitantes & $\begin{array}{l}\text { Betabloqueantes } 1,7,5,33 * ; \text { anti-inflamatório não esteroide' } \text {; biguanidas }^{\prime} \text {; hidralazina }{ }^{33} \# \text {; } \\
\text { interleucina-2 } 2^{1,7,5} \&\end{array}$ \\
\hline
\end{tabular}

* - Inclui preparações oftálmicas. Há aumento de 3 vezes no risco de desenvolvimento de reações adversas comparativamente com controlos. Estes doentes são também mais refractários à terapêutica convencional e casos de anafilaxia em doentes a tomar beta-bloqueantes têm um risco de hospitalização nove vezes superior.

\# - Aumenta o risco de desenvolvimento de quadros vasculite-like

\& - Fortemente documentado, aumentando a frequência de reações adversas tardias duas a quatro vezes 
de Witten et al. (1973) ${ }^{22}$ e Shehadi et al. (1975) ${ }^{6}$, mas têm vindo a ser desmistificados, quer em estudos multicêntricos europeus ${ }^{10}$, quer em estudos nacionais ${ }^{23,24}$.

\section{ABORDAGEM DIAGNÓSTICA}

A informação mais crucial para o diagnóstico é uma boa história clínica e a classificação da reação em imediata ou tardia. É a partir destes dados que se decidem os meios complementares de diagnóstico a usar para confirmar ou excluir o diagnóstico.

Os exames disponíveis para as reações imediatas e tardias são descritos seguidamente e estão divididos consoante são usados no momento da reação adversa ou após a mesma.

Relativamente às reações imediatas, no momento da reação pode avaliar-se a triptase e histamina séricas. Estas estão elevadas em alguns doentes com reações imediatas graves ou fatais. $O$ pico da elevação da histamina ocorre entre os 5 a 10 minutos após o início dos sintomas e retorna ao valor basal em $<1$ hora. O pico da elevação da triptase ocorre I a 2 horas após o início dos sintomas ${ }^{4}$. Alguns autores sugerem que o momento ideal para a colheita da histamina varia consoante a gravidade da reação observada: entre 5 a 15 min após o início da reação grau I; entre 15 a 30 min após o início da reação grau II; entre 30 min a 2 horas após o início da reação grau III ou IV. No caso da triptase sugerem: entre 15 a 60 min após o início da reação se grau I ou II; entre 30 min a 2 horas após o início da reação se grau III ou IV³.

Após a resolução da reação, podem realizar-se:

- Testes cutâneos: são o meio complementar de diagnóstico mais importante, embora a verdadeira sensibilidade e especificidade ainda esteja por determinar. Vários estudos internacionais e nacionais referem diferentes sensibilidades e especificidades. É encorajador o facto de dois grupos apresentarem testes cutâneos intradérmicos (TID) negativos em controlos saudáveis com MCRI com uma concentração de (I/I00), bem como o facto de os estudos mostrarem uma baixa reatividade cruzada entre $M C R I^{4,21}$. Os testes cutâneos por picada (TCP) são realizados com o MCRI puro e os TID são realizados com o MCRI em diluições de $\mathrm{I} / 1000$ até $\mathrm{I} / 10^{4}$. Quanto ao melhor momento para se realizarem os testes, pensa-se que será ente os 2 e os 6 meses após a reação. Um estudo mostrou uma frequência de testes positivos de $14 / 28$ (50\%) quando realizados 2 a 6 meses após a reação e apenas $17 / 92$ (I8\%) quando realizados antes dos 2 meses ou após os 6 meses $(p=0,0003)^{10}$. Em geral, os TCP raramente são positivos e os TID têm maior probabilidade de serem positivos quanto mais grave for a reação 10,23,25-28. Estes testes só devem ser usados se tiver ocorrido uma reação prévia. Está demonstrado que o uso de TCP ou TID como forma de pré-avaliação em doentes sem história de reações adversas não é útil para prever reações adversas ${ }^{25}$;

- IgE específica sérica: não existem testes comercialmente disponíveis, mas três grupos reportaram já anticorpos IgE específicos contra ioxaglato. No entanto, as frequências de positividade variam entre 2 e $47 \%$, 25,29 ;

- Teste de ativação dos basófilos: está descrito que a libertação de histamina é significativamente superior em indivíduos com reações prévias a MCRI comparativamente a doentes expostos a MCRI e sem reação, ou a voluntários saudáveis. Sabe-se também que os leucócitos de indivíduos atópicos libertam uma maior quantidade de histamina após exposição a MCRI do que os leucócitos de indivíduos não atópicos. No entanto, a validade do teste permanece por demonstrar ${ }^{4}$;

- Prova de provocação: é o gold standard no diagnóstico em alergologia. No entanto, pelos riscos que envolve não é uma metodologia aconselhada por rotina, em particular pela existência de MCRI alternativos. Yocum et al..$^{30}$ propuseram um pro- 
tocolo de prova de provocação com MCRI, no qual $0,1 \mathrm{~mL}$ de MCRI é administrado por via endovenosa em intervalos de 15 minutos, começando com uma diluição de $1 / 10000$ e subindo em diluições de $10 x$ até à administração de $\mathrm{I}$ a $5 \mathrm{~mL}$ do MCRI puro antes do exame. Com este protocolo, reações positivas ligeiras a moderadas foram observadas em $22 \%$ dos doentes com antecedentes de reação prévia. Apesar de este procedimento parecer ser eficaz na escolha do MCRI em doentes de alto risco, é de difícil prática por consumir muito tempo e recursos ${ }^{4}$.

Relativamente às reações tardias, no momento da reação pode realizar-se uma avaliação laboratorial geral. Apesar de a maioria das reações serem cutâneas, outros órgãos podem também estar envolvidos. Deve ser realizada uma avaliação da função renal e hepática e hemograma com contagem diferencial de leucócitos, embora não existam dados sobre a frequência de alterações laboratoriais ${ }^{4}$. Pode também realizar-se uma biópsia cutânea, podendo a histologia ajudar na avaliação e confirmação da reação alérgica ${ }^{4}$.

Após a resolução da reação, podem realizar-se:

\section{- Testes cutâneos indradérmicos e epicutâneos:} os testes epicutâneos (Epi) positivos com MCRI puro estão descritos e, apesar de parecerem específicos (um estudo com 30 controlos foi negativo em todos), não há dados certos quanto à sua sensibilidade, descrita entre 28 e $50 \%$, 10,25 . A leitura tardia dos TID (às 48 e 96 horas) é também usada e, segundo alguns autores, é mais sensível que os $\mathrm{Ep}^{5}$. Epi com MCRI puro no dorso e TID com leituras às 48 e 96 horas quando usados em conjunto aumentam a sensibilidade $^{4,10}$. Estes devem ainda ser lidos após uma semana se previamente negativos ${ }^{4}$. Quanto ao melhor momento para realizar os testes, um estudo demonstrou que $29 / 62$ (47\%) foram positivos quando realizados nos primeiros 6 meses após a reação, comparando com apenas $8 / 36(26 \%)$ realizados após os 6 meses $(p=0,02)$;

- Teste de proliferação/ativação linfocitária: não se encontra suficientemente validado, apesar de alguns trabalhos demonstrarem proliferação de linfócitos em contacto com $\mathrm{MCRI}^{4}$;

- Prova de provocação: existem já três estudos descrevendo este procedimento. Em todos os casos houve reprodução da reação inicial (exantema maculopapular) com a administração do MCRI não diluído, ainda que em quantidades consideravelmente menores do que as usadas no exame em que se desenvolveu a reação (I a $5 \mathrm{~mL}$ vs 100 a $200 \mathrm{~mL}$ ). No entanto, pelos riscos que envolve, permanece ainda uma ferramenta de investigação e não uma metodologia aconselhada por rotina ${ }^{4}$. Além deste facto, em reações de maior gravidade com risco para a vida ou sequelas permanentes (síndrome de Stevens-Johnson, necrólise epidérmica tóxica, DRESS ou pustulose exantematosa generalizada aguda) a sua realização está contraindicada.

\section{ABORDAGEM TERAPÊUTICA}

No tratamento das reações aos MCRI, os fármacos e as doses a serem utilizadas não são consensuais. $O$ Quadro 6 mostra as recomendações do American College of Radiology ${ }^{5}$. Salienta-se que reações cutâneas mais ligeiras e sem queixas por parte do doente podem não necessitar de terapêutica dirigida, tendo resolução espontânea sem quaisquer intercorrências.

Quanto à profilaxia que se pode realizar, considerando os diferentes mecanismos fisiopatológicos que implicam abordagens diferentes, não existe um tratamento único que previna o aparecimento de qualquer reação. Tal não significa que o tratamento profilático não seja importante; em especial em doentes com reações prévias a MCRI ou em doentes com fatores de risco, nos quais 
Quadro 6. Tratamento agudo das reações a meios de contrate radiológico iodados, adaptado aos fármacos existentes em Portugal ${ }^{4}$.

\begin{tabular}{|c|c|}
\hline Manifestação & Tratamento \\
\hline Urticária & Clemastina $0,025 \mathrm{mg} / \mathrm{kg} /$ dose (máx $2 \mathrm{mg}$ ) EV \\
\hline Broncospasmo & $\begin{array}{l}\text { Preservar acesso EV } \\
\text { Monitorizar sinais vitais } \\
\text { Oxigénio por máscara } 6-10 \mathrm{~L} / \mathrm{min} \\
\text { Salbutamol } 4 \text { puffs ( } 100 \mathrm{cmg} / \mathrm{puff}) \\
\text { Ponderar adrenalina IM ou IV* }\end{array}$ \\
\hline Edema laríngeo & $\begin{array}{l}\text { Preservar acesso EV } \\
\text { Monitorizar sinais vitais } \\
\text { Oxigénio por máscara } 6-10 \mathrm{~L} / \mathrm{min} \\
\text { Adrenalina IM ou EV* }\end{array}$ \\
\hline Hipotensão & $\begin{array}{l}\text { Preservar acesso EV } \\
\text { Monitorizar sinais vitais } \\
\text { Oxigénio por máscara } 6-10 \mathrm{~L} / \mathrm{min} \\
\text { Elevanção dos membros inferiores } \\
\text { Soro fisiológico EV } 10-20 \mathrm{~mL} / \mathrm{kg} \text { até IL }\end{array}$ \\
\hline $\begin{array}{l}\text { Taquicardia (reação de hipersensibilidade) } \\
\text { associada à hipotensão }\end{array}$ & Adrenalina IM ou EV* \\
\hline $\begin{array}{l}\text { Bradicardia (reação vasovagal) associada } \\
\text { à hipotensão }\end{array}$ & $\begin{array}{l}\text { Atropina EV } 0,2 \mathrm{~mL} / \mathrm{kg} \text { de solução } 0,1 \mathrm{mg} / \mathrm{mL}(0,02 \mathrm{mg} / \mathrm{kg}) \text {. } \\
\text { Dose única mínima: } 0,1 \mathrm{mg} \text {. Dose única máxima: } 0,6 \text { - I mg. Dose máxima } \\
\text { total: I mg para crianças, } 2 \mathrm{mg} \text { para adolescentes e adultos. } \\
\text { Administração concomitante de soro fisiológico EV. }\end{array}$ \\
\hline Prevenção de reações "rebound" & $\begin{array}{l}\text { Hidrocortisona EV } 5 \text { mg/kg (máx 200mg) } \\
\text { ou } \\
\text { Metilprednisolona EV I mg/kg (máx } 40 \text { mg) }\end{array}$ \\
\hline
\end{tabular}

* Adrenalina IM (intramuscular) 0,0I mL/kg de solução I:I.000 (0,0I mg/kg), até máx 0,50 mL $(0,50 \mathrm{mg})$, que pode ser repetida cada 5 - 15 minutos; adrenalina EV 0,I mL/kg de solução I: $10.000(0,01 \mathrm{mg} / \mathrm{kg})$; administrada lentamente com soro fisiológico; dose máxima $0,15 \mathrm{mg}(\mathrm{I}, 5 \mathrm{~mL})$ para $\leq 30 \mathrm{~kg}$ e $0,50 \mathrm{mg}(5,0 \mathrm{~mL})$ se $>50 \mathrm{~kg}$.

a probabilidade de reação adversa diminui significativamente com uso de terapêutica profilática ${ }^{8}$.

$\mathrm{Na}$ literatura existem várias recomendações de organizações profissionais e de grupos de estudo referindo diferentes regimes profiláticos. Os problemas de uniformização devem-se à inexistência de estudos randomizados controlados por placebo, às questões éticas relacionadas com a criação destes estudos e à constante evolução e modificação dos MCRI usados na prática clínica $^{1,4,5,8,29}$. Contudo, todas as recomendações têm o primeiro passo em comum: identificação do MCRI causador da reação e a escolha de um MCRI alternativo. Della-Torre et al. ${ }^{29}$ sugeriu um algoritmo para a seleção de um MCRI baseada na história e resultados de testes cutâneos (TCP, ID e Epi).

Quanto à terapêutica profilática a realizar, o estudo mais relevante é o de Tramèr et al., que fez uma pesquisa sistemática de estudos randomizados de esquemas de profilaxia antes de exames com MCRI e os seus resultados. Os estudos analisavam anti-histamínicos anti-HI (hidroxizina, clemastina, clorfeniramina, dimenidrato), corticoides (betametasona, dexametasona, metilprednisolona e prednisolona) e combinação de anti-histamínicos anti-HI e $\mathrm{H} 2$ (clemastina + cimetidina). Nenhum estudo testou a combinação de corticoides com anti-histamínicos ${ }^{31}$. De uma forma global, os resultados 
parecem animadores, demonstrando que: I) os anti-histamínicos e os corticoides diminuem o risco de desenvolvimento de sintomas cutâneos e também respiratórios; 2) a combinação clemastina + cimetidina demonstrou diminuição estatisticamente significativa da prevenção de angioedema; 3) os corticoides diminuem o risco de uma reação com risco de vida (hipotensão), mas precisam de ser medicados cerca de 100 a 150 doentes desta forma para prevenir esta reação em I doente.

Considerando o efeito protetor no desenvolvimento de sintomas cutâneos, respiratórios e cardiovasculares, os autores consideram que os corticoides e anti-histamínicos devem ser usados sempre que o doente apresente fatores de risco (nomeadamente história de reação prévia a MCRI), no sentido de tentar prevenir uma reação adversa. Neste sentido, o Serviço de Imunoalergologia do Hospital de Santa Maria desenvolveu e aplica os seguintes protocolos em doentes com facto de risco para reações adversas a MCRI que vão realizar novo exame com MCRI:

- Se o doente apresenta apenas fatores de risco para reação adversa (asma brônquica, cardiopatia isquémica, diabetes mellitus, insuficiência renal crónica, mieloma, policitemia, drepanocitose ou terapêutica com AINES, betabloqueantes, IL-2 ou biguanidas), mas sem história de reação prévia a MCRI, deve realizar metilprednisolona 40mg EV 2 horas antes do exame e metilprednisolona $32 \mathrm{mg}$ PO (ou prednisolona $40 \mathrm{mg}$ PO) 12 horas antes do exame;

- Se o doente apresenta história de reação prévia a MCRI, independentemente de ter ou não outros fatores de risco, deve realizar 13 e 7 horas antes do exame $50 \mathrm{mg}$ de prednisolona e $10 \mathrm{mg}$ de loratadina $10 \mathrm{mg}$; I hora antes do exame hidrocortisona 200 $\mathrm{mg} \mathrm{EV}$, clemastina $2 \mathrm{mg}$ diluída em $100 \mathrm{~mL}$ de soro fisiológico EV e ranitidina $50 \mathrm{mg} \mathrm{EV}$.

A escolha de MCRI alternativo baseia-se nos resultados dos testes cutâneos intradérmicos e epicutâneos ou, caso a investigação ainda não esteja completa, adaptando o algoritmo de Della-Torre et a ${ }^{29}$.

No contexto da profilaxia é ainda importante referir as reações breakthrough. Estas reações foram identificadas pela primeira vez em 1949, desenvolvem-se apesar da pré-medicação dos doentes com anti-histamínicos e/ou corticoides e podem ocorrer quer em doentes que fazem pré-medicação por apresentarem fatores de risco, quer em doentes que fazem pré-medicação pelo principal fator de risco - a história de reação prévia ${ }^{3,4,31}$. Quando ocorrem, as reações breakthrough tendem a ser similares às iniciais em $85 \%$ dos casos e graves ou com risco de vida em $24 \%$ dos $\operatorname{casos}^{31}$. Globalmente, a taxa destas reações após a administração prévia de corticoide é estimada em $10 \%{ }^{21}$.

Em alguns casos, apesar de pré-medicação e da tentativa de escolha de um MCRI alternativo, pode ser imprescindível a realização de um exame com um meio de contraste ao qual o doente já fez reações. Nestes casos, pode-se optar pela dessensibilização. Esta não é uma prática comum e poucos dados existem sobre tentativas de dessensibilização.

Em 2014, Gandhi et al. elaborou um protocolo de dessensibilização ao iodixanol com bons resultados, numa doente com história de reações adversas e com necessidade de uma coronariografia urgente ${ }^{32}$.

\section{CONCLUSÕES}

As reações adversas a MCRI são cada vez mais frequentes, seja porque estes fármacos se tornam mais usados na prática clínica ou porque há mais casos identificados/reportados. No entanto, a constante evolução dos MCRI e a existência de comorbilidades e fármacos administrados concomitantemente muitas vezes dificulta a correta interpretação destas reações.

Os pontos mais importantes na avaliação destas reações são a identificação do MCRI responsável e a realização de uma boa história clínica, de forma a orientar a 
ação do imunoalergologista. A sua atuação deverá ter como foco principal a confirmação de que se tratou de uma reação adversa (seja imunológica ou não) ao fármaco, evitando a restrição excessiva do uso dos MCRI. Após identificação do agente causal, é importante fazer a evicção do MCRI responsável, escolher um MCRI (LOCM) alternativo mediante o resultado de testes cutâneos (TCP, TID, Epi) e administrar pré-medicação com corticoides e anti-histamínicos como profilaxia de uma eventual reação em doentes com reação prévia ou com outros fatores de risco para o desenvolvimento de reações adversas.

Contacto:

João Marcelino

E-mail: JLAM_1987@sapo.pt

\section{REFERÊNCIAS}

I. Singh J, Daftary A. lodinated contrast media and their adverse reactions. J Nucl Med Technol 2008;36:69-74.

2. Kvedariene V, Martins P, Rouanet L, Demoly P. Diagnosis of iodinated contrast media hypersensitivity: Results of a 6-year period. Clin Exp Allergy 2006;36:1072-7

3. Dewachter P, Tréchot P, Mouton-Faivre C. "lodine allergy": point of view. Ann Fr Anesth Reanim 2005;24:40-52.

4. Brockow K, Christiansen C, Kanny G, Clément O, Barbaud A, Bircher A, et al. ENDA; EAACl interest group on drug hypersensitivity. Management of hypersensitivity reactions to iodinated contrast media. Allergy 2005;60:150-8.

5. Ellis J, et al. ACR manual on contrast media. Version $10^{\text {th }}$ Ed. USA: American College of Radiology; 2015.

6. Shehadi WH. Adverse reactions to intravascularly administered contrast media. A comprehensive study based on a prospective survey. Am J Roentgenol Radium Ther Nucl Med 1975; 124:145-52.

7. Webb JA, Stacul F, Thomsen HS, Morcos SK; Members of the contrast media safety committee of the European Society of Urogenital Radiology. Late adverse reactions to intravascular iodinated contrast media. Eur Radiol 2003;13:181-4.

8. Liccardi G, Lobefalo G, Di Florio E, Di lorio C, Occhiochiuso L, Romano L, et al. Cardarelli Hospital Radiocontrast Media and Anesthetic-Induced Anaphylaxis Prevention Working Group. Strategies for the prevention of asthmatic, anaphylactic and anaphylactoid reactions during the administration of anesthetics and/or contrast media. J Investig Allergol Clin Immunol 2008; 18:1-II.
9. Lasser EC, Kolb WP, Lang JH. Letter: Contrast media activation of serum complement system. Invest Radiol 1974;9:6.

10. Brockow K, Romano A, Aberer W, Bircher AJ, Barbaud A, Bonadonna $P$, et al. European Network of Drug Allergy and the $\mathrm{EAACl}$ interest group on drug hypersensitivity. Skin testing in patients with hypersensitivity reactions to iodinated contrast media - a European multicenter study. Allergy 2009;64: 234-4I.

II. Böhm I, Schild HH. A practical guide to diagnose lesser-known immediate and delayed contrast media-induced adverse cutaneous reactions. Eur Radiol 2006;16:1570-9.

12. Katayama H, Yamaguchi K, Kozuka T, Takashima T, Seez P, Matsuura $\mathrm{K}$. Adverse reactions to ionic and nonionic contrast media. A report from the Japanese Committee on the Safety of Contrast Media. Radiology 1990;175:621-8.

13. Schabelman E, Witting $M$. The relationship of radiocontrast, iodine, and seafood allergies: a medical myth exposed. J Emerg Med 2010;39:70I-7.

14. Stellato C, de Crescenzo G, Patella V, Mastronardi P, Mazzarella B, Marone G. Human basophil/mast cell releasability. Heterogeneity of the effects of contrast media on mediator release. J Allergy Clin Immunol 1996;97:838-50.

15. Genovese A, Stellato C, Marsella CV, Adt M, Marone G. Role of mast cells, basophils and their mediators in adverse reactions to general anesthetics and radiocontrast media. Int Arch Allergy Immunol 1996;110:13-22.

16. Ring J, Arroyave CM, Frizler MJ, Tan EM. In vitro histamine and serotonin release by radiographic contrast media (RCM). Complement-dependent and-independent release reaction and changes in ultrastructure of human blood cells. Clin Exp Immunol 1978;32:105-18.

17. Kolb WP, Lang JH, Lasser EC. Nonimmunologic complement activation in normal human serum induced by radiographic contrast media. J Immunol 1978;121:1232-8.

18. Till G, Rother U, Gemsa D. Activation of complement by radiographic contrast media: generation of chemotactic and anaphylatoxin activities. Int Arch Allergy Appl Immunol 1978;56:543-50.

19. Heideman M, Jacobsson B, Lindholm N. Activation of the complement system by water-soluble contrast media. A preliminary report. Acta Radiol Diagn (Stockh) 1976;17:733-6.

20. Kanny G, Pichler W, Morisset M, Franck P, Marie B, Kohler C, et al. T cell-mediated reactions to iodinated contrast media: evaluation by skin and lymphocyte activation tests. J Allergy Clin Immunol 2005; II5:179-85.

21. Brockow K. Immediate and delayed cutaneous reactions to radiocontrast media. Chem Immunol Allergy 2012;97:180-90.

22. Witten DM, Hirsch FD, Hartman GW. Acute reactions to urographic contrast medium: incidence, clinical characteristics and relationship to history of hypersensitivity states. Am J Roentgenol Radium Ther Nucl Med 1973;119:832-40. 
23. Carvalho S, Marcelino J, Cabral Duarte F, Costa AC, Pereira-Barbosa M. "Alergia ao iodo" contra-indica o uso de meios de contraste iodados? A propagação de um mito. Rev Port Imunoalergologia 2015 (Suppl I):79.

24. Marcelino J, Carvalho S, Cabral Duarte F, Costa AC, Pereira-Barbosa M. Alergia ao camarão e a meios de contraste iodados: Mito ou realidade?. Rev Port Imunoalergologia 2015 (Suppl I):27.

25. Ahn YH, Koh YI, Kim JH, Ban GY, Lee YK, Hong GN, et al. The potential utility of iodinated contrast media (ICM) skin testing in patients with ICM hypersensitivity. J Korean Med Sci 2015; 30:245-5I.

26. Silva P, Costa AC, Caiado J, Duarte FC, Soares J, Lopes A, et al. Alergia a meios de contraste radiológicos - Investigação numa Consulta de Imunoalergologia. Rev Port de Imunoalergologia 20II;19(Supl I):30.

27. Cabral Duarte MFM, Costa AC, Silva PM, Pedro E, Pereira-Barbosa M. Alergia a meios de contraste iodados numa consulta de imunoalergologia. Braz J Allergy Immunol 20 I3; I:87.

28. Dewachter P, Laroche D, Mouton-Faivre C, Bloch-Morot E, Cercueil JP, Metge L, et al. Immediate reactions following iodinated contrast media injection: a study of 38 cases. Eur J Radiol 2011;77:495-501.

29. Della-Torre E, Berti A, Yacoub MR, Guglielmi B, Tombetti E, Sabbadini MG, et al. Proposal of a skin tests based approach for the prevention of recurrent hypersensitivity reactions to iodinated contrast media. Eur Ann Allergy Clin Immunol 2015;47:77-85.

30. Yocum MW, Heller AM, Abels RI. Efficacy of intravenous pretesting and antihistamine prophylaxis in radiocontrast media-sensitive patients. J Allergy Clin Immunol 1978;62:309-13

3I. Tramèr MR, von Elm E, Loubeyre P, Hauser C. Pharmacological prevention of serious anaphylactic reactions due to iodinated contrast media: systematic review. BMJ 2006;333:675.

32. Gandhi S, Litt D, Chandy M, Nguyen BM, Jindal NL, Tarlo SM, et al. Successful rapid intravenous desensitization for radioiodine contrast allergy in a patient requiring urgent coronary angiography. J Allergy Clin Immunol Pract 2014;2:10I-2.

33. Morcos SK, Thomsen HS, Exley CM; Members of Contrast Media Safety Committee of European Society of Urogenital Radiology (ESUR). Contrast media: interactions with other drugs and clinical tests. Eur Radiol 2005;15:1463-8. 